\title{
The Role of Emergency Medical Services in Geriatrics: Bridging the Gap between Primary and Acute Care
}

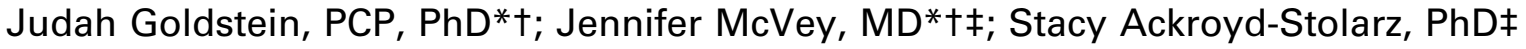

\section{ABSTRACT}

Caring for older adults is a major function of emergency medical services (EMS). Traditional EMS systems were designed to treat single acute conditions; this approach contrasts with best practices for the care of frail older adults. Care might be improved by the early identification of those who are frail and at highest risk for adverse outcomes. Paramedics are well positioned to play an important role via a more thorough evaluation of frailty (or vulnerability). These findings may inform both pre-hospital and subsequent emergency department (ED) based decisions. Innovative programs involving EMS, the ED, and primary care could reduce the workload on EDs while improving patient access to care, and ultimately patient outcomes. Some frail older adults will benefit from the resources and specialized knowledge provided by the ED, while others may be better helped in alternative ways, usually in coordination with primary care. Discerning between these groups is a challenge worthy of further inquiry. In either case, care should be timely, with a focus on identifying emergent or acute care needs, frailty evaluation, mobility assessments, identifying appropriate goals for treatment, promoting functional independence, and striving to have the patient return to their usual place of residence if this can be done safely. Paramedics are uniquely positioned to play a larger role in the care of our aging population. Improving paramedic education as it pertains to geriatrics is a critical next step.

\section{RÉSUMÉ}

La prestation des soins aux personnes âgées occupe une place importante dans les services médicaux d'urgence
(SMU). Les systèmes de SMU étaient conçus au départ pour traiter des affections aiguës isolées, ce qui est très différent des pratiques exemplaires en matière de soins aux personnes âgées fragiles. Le repérage précoce des personnes âgées fragiles, fortement prédisposées à des événements défavorables pourrait améliorer la prestation des soins. Les ambulanciers paramédicaux sont bien placés pour jouer un rôle important dans une évaluation approfondie du degré de fragilité (ou de vulnérabilité), et les résultats obtenus peuvent éclairer les décisions prises par les fournisseurs de services préhospitaliers et, par la suite, dans les services d'urgence (SU). Des programmes innovateurs de SMU, de soins dans les SU et de soins de base pourraient réduire la charge de travail dans les SU tout en améliorant l'accès aux soins et, en dernier ressort, les résultats cliniques. Certaines personnes âgées fragiles pourraient profiter des ressources disponibles dans les SU et du bagage cumulé de connaissances spécialisées, tandis que d'autres profiteraient davantage d'autres solutions, habituellement d'une meilleure coordination des soins de base. Toutefois, cela vaudrait la peine de faire davantage de recherche afin de distinguer les deux groupes. Dans un cas comme dans l'autre, il faudrait donner des soins au bon moment, en plus de déterminer la nécessité de fournir des soins d'urgence ou des soins de courte durée; d'évaluer le degré de fragilité et de mobilité; d'établir la pertinence des buts du traitement; de promouvoir l'autonomie fonctionnelle et de favoriser autant que possible le retour en toute sécurité au lieu habituel d'habitation. Les ambulanciers paramédicaux occupent une place privilégiée pour jouer un rôle accru dans la prestation des soins à la population âgée. L'amélioration de leur formation en gériatrie est donc la prochaine étape cruciale.

Keywords: EMS, Paramedic, Aged, Geriatrics, Frail Elderly

From the *Emergency Health Services Nova Scotia, Dartmouth, NS; †Division of Emergency Medical Services; and $\neq$ Department of Emergency Medicine, Dalhousie University, Halifax, NS.

Correspondence to: Judah Goldstein, Emergency Health Services Nova Scotia, 300-239 Brownlow Ave, Dartmouth, NS, B3B 2B2; Email: Judah. goldstein@emci.ca 


\section{INTRODUCTION}

Older adults ( $\geq 65$ years of age) are the most rapidly growing segment of society. In 2011, there were five million people over the age of 65 in Canada; this is expected to double by $2036 .{ }^{1}$ Older age is a major determinant of EMS and ED use; ${ }^{2}$ age does not fully explain usage trends, particularly in those over 85 years $^{3}$. Other explanations include an increased proportion of older adults living alone, reduced capacity of caregivers, and difficulties accessing primary care. ${ }^{3}$ Close to half of EMS emergency responses in Canadian populations (and other developed countries) are for older adults, ${ }^{4-6}$ and it is expected that EMS usage will continue to rise ${ }^{3}$.

Patient complexity will also have an impact on resource requirements, in addition to the increasing call volume. Frailty is common in older adults seeking emergency care. ${ }^{7-9}$ Frailty can be characterized as a state of weakness, slowness, weight loss, exhaustion, and low physical activity. ${ }^{10}$ Alternatively, it has been described as an accumulation of deficits or health problems. ${ }^{11}$ Frailty is an independent predictor of poor outcomes in the ED population, ${ }^{7,12}$ and is also predictive of morbidity, mortality, and adverse events in critically ill patients ${ }^{13}$. It can be challenging for ED staff to have the time and resources required to accurately identify frailty. This often requires collateral details not available in the ED, and these details may be difficult to obtain if family or caregivers are not present. Even so, much of the information necessary for determining frailty could be gathered within the patient's residence. Paramedics are present in the living environments of patients, and are able to obtain information that may suggest whether the patient is at risk, or appropriately resourced in their home (e.g., cleanliness, lack of food, medication management, mobility aids). The opportunity for paramedics to gather more detailed information from the homes and caregivers of older adults exists. ${ }^{9}$ The acquisition and documentation of these data could form mandatory fields for the patient's pre-hospital care record.

Even though we must be cognizant of EMS time spent on task, gathering valid information and ensuring that it is transferred effectively during patient handover could lead to improved system efficiencies. The length of time paramedics spend with patients is increasing, due to ED overcrowding (off-load delay) ${ }^{14}$ and prolonged transports resulting from the closure of smaller centers.
This contact time may represent an opportunity for paramedics to play a larger role, by using it to perform more detailed assessments, and to grade frailty. This information would inform subsequent decisions made in the ED phase of care, pertaining to treatment goals, diagnostic tests and treatments provided, engagement of human resources (e.g., social work), as well as patient disposition.

Opportunities currently exist to better integrate EMS systems into the health care continuum during a health crisis. Paramedics are in an ideal position in that they span the divide between acute and community care. They can be active collaborators in care provision, are accessible, and can play a supportive role to other health care practitioners during a health crisis. This new approach strives to deliver the right resources (equipment, procedural skills, and cognitive skills) to the right patient in the right place at the right time. ${ }^{15}$ EMS can facilitate this process.

Novel programs are being developed to better integrate primary, home, continuing, and acute care by engaging paramedics in non-traditional ways. ${ }^{16,17}$ "Traditional scope" EMS refers to the provision of out-of-hospital acute care and transport to the ED by ambulance. This can now be thought of as a component of what contemporary EMS systems may offer. "Expanded scope" EMS refers to a variety of programs that engage paramedics in non-traditional scopes of practice, or in novel roles in the health care system. "Community paramedicine" represents a diverse array of programs involving paramedics with expanded scopes or roles in non-acute settings (e.g., fall prevention, wellness checks, chronic disease monitoring). Paramedics performing detailed geriatric assessments during acute care is one way in which the scope of practice may be expanded. We will argue why this may be of benefit.

Another opportunity exists "upstream" during the acute phase of care, before the paramedics have even initiated transport of the patient to the ED. Paramedics could learn to screen for medical necessity of an ED visit. A paramedic with additional training and assessment skills, armed with alternative referral and disposition options, could safely determine which older adults require an ED visit and which are better cared for by community resources. Many EMS activations are truly acute, emergent, and unavoidable; however, EMS use is also engaged in the context of persistently unmet chronic needs that culminate in a perceived health crisis. When an unmet health care need is present, the 
default is often to call EMS. The caller may not necessarily want to go to the ED, but has exhausted their resources. ${ }^{18,19}$ It is conceivable that in such circumstances resources could be urgently mobilized in the community setting by paramedics, should the context allow.

We will illustrate examples of expanded-scope EMS systems designed to better meet the needs of older adults. These examples often provide alternatives to ED transport, and "bridging" of the acute phase of care back to primary or community-based care. Innovative programs could lead to more efficient, timely, and efficacious care that better aligns with the priorities of older patients, focusing on maintaining function and independence. ${ }^{20}$

We will also address controversies surrounding the paramedic scope expanding to include such things as frailty assessments, the determination of medical necessity for an ED visit, and the selection of appropriate alternative care pathways. Such expansion may require time away from traditional duties. For instance, would we see prolonged response times for acute/critical cases if paramedics are busy doing frailty assessments? Why are paramedics the best practitioners to assume some of these roles? What educational requirements are needed to ensure paramedics are adequately trained to safely take on these additional responsibilities? We will discuss these controversies, alongside arguments in support of expanding the scope and role of paramedics in geriatric care.

\section{FRAILTY: SCREENING AND ASSESSMENT}

Paramedics are easily accessible, and frequently provide care to society's most vulnerable. In geriatrics, this encompasses those with a high burden of frailty. The extent of patient risk can be better understood by discerning between those who are fit and acutely ill versus frail and acutely ill. Frailty measures have been developed to help clinicians quantify the degree of risk for adverse outcomes and health care needs. Frailty has been described as a "state variable" 21 akin to temperature, and an important health indicator for older adults. Depending on the measure, it may also inform care planning and goal setting. More research is required to understand whether knowing about frailty can lead to improvements in care. ${ }^{22}$

Frailty measures exist despite the lack of a consensus frailty definition. Three definitions are described here.
1) The Clinical Frailty Scale (CFS) is simple to use and appealing to clinicians in busy clinical practice; however, it lacks validation in multiple settings and the precision of other measures. ${ }^{23}$ Clinicians require knowledge about the patient's comorbidities, mobility, and function in order for it to be used. 2) Frailty has been described as a syndrome or collection of performance-based health problems: slowness, weakness, self-reported decrease in activity, exhaustion, and unintended weight loss. ${ }^{10}$ If three of these five problems are present, the person is considered frail. This approach has been well studied, with its main drawback being its difficulty to implement in clinical practice. 3) The Frailty Index (FI) is a count of health problems. ${ }^{21}$ Typically, 30-40 variables are considered, with rules guiding their inclusion into the measure. If a person has 10 problems out of a possible 40, for example, their FI would be 0.25 . The FI has reproducible mathematical properties, including an upper limit to frailty at $0.7 .^{21}$ This limit to frailty has important clinical implications. A FI has been operationalized by counting health deficits from a standard Comprehensive Geriatrics Assessment (FI-CGA). ${ }^{24}$ More recently, a FI based on care-partner-reported information (CP-FI-CGA) was derived in the EMS setting. ${ }^{9,25}$ This approach aimed to minimize the workload for health care practitioners while capturing the information that is vital for frailty determination. The benefits of the FI are in its precision, ability to stratify risk, and inclusion of a variety of age-associated health problems. Its main barrier for use is the need for at least 30 items. Most of the items would be known or easily obtained through a routine assessment, and often include function, mobility, and social factors. Whether the routine assessment of frailty can lead to improvements in care is not known. Frailty screening may aid in determining who might need a more comprehensive inhospital or community-based assessment following the health crisis. Further, frailty measures can identify someone who is frail and acutely ill compared to someone who is fit and acutely ill. This distinction may be critical when determining treatment options. Often this differentiation is difficult in the ED, where people are removed from their living environment, typically immobile, and dependent on others during their course of care. Paramedics can capture valuable information from brief home, patient, and caregiver assessments/ interviews that may help to present a more accurate picture of the patient's baseline health status. In the absence of a caregiver, this assessment becomes more 
difficult; however, for the majority of patients, it is still possible.

In our "single problem at a time" approach to care, frail older adults are at risk for under-triage and inadequate care due to the fragmentation of service provision within the health care system. ${ }^{26}$ Recently, the British Geriatrics Society (BGS) has recommended that all older adults be evaluated for frailty during a health care encounter. ${ }^{27,28}$ This may be a challenging proposition in the EMS/ED context, but paramedics may be ideally positioned to perform this evaluation during the time they would spend with the patient anyway. This would have very little impact on the system in terms of time they are available for traditional scope responsibilities. It could also be argued that this would improve traditional scope care.

Paramedics have also evaluated frailty using the brief CFS, with moderate agreement between paramedics, specialists, and the more comprehensive FI-CGA. ${ }^{29}$ A FI derived from care-partner-reported information, in the EMS setting, provided comparable predictive discriminatory power for serious adverse events as an in-hospital FI-CGA. ${ }^{9}$ These results demonstrate the feasibility of measuring frailty in EMS, and validity in terms of being able to stratify patients by frailty level. Further research is necessary to refine these estimates and to determine the impact on care.

Paramedics could conduct early frailty screening and assessment for both transported and non-transported geriatric patients. This information could then be used to prioritize patients in need of medical evaluation. This information could be passed on to subsequent care providers as a current snapshot measure of health status. The CP-FI-CGA also asks respondents to provide a baseline level of health two weeks prior to the health crisis, providing an estimate of change. ${ }^{9}$ EMS has been recognized for its potential role in public health, with research focusing on EMS screening for immunization need, ${ }^{30}$ falls, ${ }^{31}$ and referral to social services ${ }^{32}$. Frailty screening could inform decisions regarding transport to emergency care, referral to specialized geriatric services, and other community-based support services such as home care. Improved communication with primary care would allow this valuable information to be shared with care providers.

A more amenable approach to identifying vulnerable older adults may be risk screening in the EMS/ED context. Risk screening has received considerable attention. These tools may be proxy markers of frailty. ${ }^{33}$ General risk-screening tools have been evaluated in the ED, with the two most commonly studied being the Identification of Seniors at Risk (ISAR) ${ }^{34}$ and Triage Risk Screening Tool (TRST) ${ }^{35}$. The ISAR is a self- or caregiver-completed, six-item measure administered during the ED visit, either upon early presentation or prior to discharge. It includes questions pertaining to premorbid and acute functional dependence, recent hospitalization (within six months), impaired memory, impaired vision, and polypharmacy (taking more than three medications). ${ }^{34}$ The TRST evaluates six items, including cognitive impairment, difficulty walking or transferring, recent falls, living alone with no available caregiver, taking five or more prescription medications, ED use in previous 30 days or hospitalization in previous 90 days, and registered nurse (assessor) concern. Two or more risk factors or the presence of cognitive impairment leads to a designation of "high risk." ${ }^{35}$ One pre-hospital risk screening measure exists, ${ }^{36}$ but has not been widely evaluated. Paramedics assessing elders at risk of independence loss (PERIL) has been evaluated in three EMS settings. ${ }^{37}$ Risk screening could minimize under-triage in older adults, identify those at risk for short-term decline upon ED discharge, and identify the need for a more thorough assessment and intervention. ${ }^{38}$ Risk/frailty screening represents an opportunity for paramedics to expand their role in the care of older patients. New or enhanced services incorporating this practice should be studied to assess proficiency, patient impact, and the impact on the traditional scope aspects of the system.

\section{EXPANDING PARAMEDIC SCOPE AND ROLE: ALTERNATIVES TO ED TRANSPORT}

The accuracy with which paramedics are able to determine "medical necessity" (of an ED visit) is controversial. ${ }^{39-42}$ EMS providers could differentiate between patients who would benefit from acute care in the ED, and those with chronic problems and unmet (or changing) needs that may be better served in the community with expanded assessment skills, guidelines, and medical oversight. Systems endorsing this determination are variable, and patient safety certainly hinges on the robustness of paramedic training, medical oversight, and practice parameters. Some systems have had positive results with programs designed for the care of older adults when additional training is provided for paramedics, and timely follow-up occurs. ${ }^{16,40}$ 
A randomized controlled trial ${ }^{40}$ from the United Kingdom reports positive findings of an expanded scope paramedicine program whereby older adults in the community with minor illness or injury received treatment without transport after calling 999. Paramedics mobilized community resources and arranged follow-up from the scene.

Jensen et al. ${ }^{16}$ describe a Halifax, Nova Scotia-based program whereby expanded scope paramedics respond to select 911 calls at long-term care (LTC) facilities. The paramedic conducts a detailed assessment, speaks with the patient's family or next-of-kin if necessary, then consults over the phone with both a geriatric care family physician and emergency medicine physician. A care plan is designed, which may include transport to the ED immediately ( $6 \%$ of patients), delayed transport in order to avoid peak times and off-load delays (24\% of patients), or a plan is devised such that the patient may remain at the facility where further tests/care/follow-up takes place (70\% of patients). ${ }^{16}$ One of the most novel aspects of the program reflects the central role of the paramedic during end-of-life decisions, and their provision of palliative care in the LTC setting. The program often allows patients to receive care according to their overall goals. Appropriate medical oversight and ongoing quality review ensure patient safety.

There are other Canadian illustrations of expanded scope or role systems designed to meet the unique needs of older adults. The EMS system in the County of Renfrew, Ontario services a predominantly rural community, with challenges in terms of access to health and other services. ${ }^{43}$ Their "Aging at Home" program identifies individuals who are on the waiting list for a LTC bed, but who could safely remain at home while waiting if some supports were provided. Participants are given a call device which activates a response by a paramedic or personal support worker, as opposed to 911. Paramedics involved in the program receive additional training to prepare them for this role. Early results suggest improved utilization of the health care system. In 129 interactions, 114 (88.4\%) did not result in 911 activation, and $86(66.7 \%)$ were fully managed at home. $^{44}$

The Toronto CREMS (Community Referrals by EMS) Program takes advantage of the fact that paramedics may be the first point of contact in the health care continuum. Paramedics identify patients at risk, and make referrals directly to home care services that can be placed within two weeks, with patient consent.
If the patient refuses, they are followed up on by a community paramedic. ${ }^{45}$ Further evaluation of community paramedic programs is ongoing. ${ }^{46}$ There is clearly growing interest regarding the safe treatment of ambulance patients in alternative settings as opposed to the ED, and the mobilization of resources to keep patients safe at home. ${ }^{47,48}$ Emerging EMS programs that use expanded scope paramedics with enhanced skill sets and locally adapted protocols will require close scrutiny to ensure patient care is not compromised while alternative care pathways are pursued. Most of the literature documenting the experience of these programs is descriptive in nature. As with any expanded scope initiative, one must consider the costs versus benefits. If the expanded system design engages paramedics during "down time" while on regular duty, traditional scope emergencies, for instance, may suffer from delayed response times. The system expansion may also represent the addition of resources to a traditional EMS system. If this is the case, one must consider whether there is benefit to the patient and health care system overall, in order to justify the additional expense. It is conceivable that these programs represent an added efficiency when the saved expense of avoidable patient ED visits and hospital admissions are considered. Some programs have integrated paramedic pathfinders into the traditional role of EMS. ${ }^{47}$ In this model, ground ambulance paramedics use either a medical or trauma pathway to determine whether patients can be provided with self-care advice, referred to primary care, or transported to urgent care or EDs. ${ }^{47}$

\section{GERIATRICS EDUCATION FOR EMS}

The role of EMS in the care of older adults, particularly in the presence of frailty, is changing. Given that paramedics care for older adults frequently, it seems reasonable that they require more knowledge about health problems in this demographic, including common emergency presentations in frail older adults. ${ }^{27}$ The Canadian Fournal of Emergency Medicine is highlighting novel programs and knowledge gaps, and serving as a place for geriatric-focused EMS research. There is a critical shortage of geriatrics-prepared health care professionals; ${ }^{49}$ this includes paramedics. Currently, paramedics receive very little geriatric-specific education in Canada. A similar trend had been noted in the US, which led to the development of the GEMS (Geriatric 
Education for EMS) Program by the American Geriatrics Society and the National Council of State Emergency Medical Services Training Coordinators (www.gemssite.com). ${ }^{50,51}$ GEMS is a national continuing education curriculum designed to help pre-hospital providers better care for older adults. Shah et al. (2008) demonstrated improved comfort levels regarding caring for older adults after rural EMS providers attended the GEMS Program. ${ }^{50}$ Programs that include core principles of geriatric care should be included in pre-hospital provider education, both during their primary education, and during continuing medical education. ${ }^{51,52}$

Expanded scope paramedicine, including more detailed geriatric care, should become part of the National Occupational Competency Profile for paramedic training. This education is required as EMS systems are likely to continue to extend beyond the traditional scope. Paramedics are likely to play a larger role in the detailed assessment and community-based care of older adults. Enhancing the approach to older patients will prepare paramedics to understand the impact of frailty and dementia, as well as inform decisions around medical necessity of an ED visit, determining care paths, collaborating with other care providers, and making appropriate referrals for specialized services. Currently, expanded scope EMS programs often include in-house training for paramedics selected to partake in such programs. There is an opportunity to standardize this training to some extent, for instance, by paramedic schools providing opportunities to earn diplomas or certificates in expanded areas of practice such as geriatrics.

\section{CONCLUSION}

Older adults often require the services of EMS, and many of these patients are frail. Frailty evaluation will help to improve decision-making in the acute care setting, whether the findings inform pre-hospital or subsequent decisions made in the ED. In a fully integrated health care system, EMS providers would also have access to advanced care plans that can be followed at times of a health crisis, so that patients get the type of care they desire in their preferred location when the need arises.

More detailed geriatric assessments are also likely to occur as part of expanded scope EMS systems, sometimes with alternative care paths that don't include transport to the ED. Paramedic determination of medical necessity, and programs that aim to bring resources to the patient instead of the patient to the ED, often enhance system outcomes (e.g., ED utilization), but such programs will need to be closely examined to ensure the quality and efficiency of patient care are maintained. Finally, paramedics will require additional geriatric-focused education if they are to better care for our aging population. This would apply to all paramedics working in a traditional scope capacity, and even more so to expanded scope paramedics making higher-level decisions for geriatric patients. In the face of a rapidly growing aging population, paramedics are an invaluable part of the health care team and are especially well positioned to help bridge acute and community care.

Competing Interests: None to declare.

\section{REFERENCES}

1. Statistics Canada. Estimates of population, by age group and sex for Fuly 1, Canada, provinces and territories, annual (CANSIM Table 051-0001). Ottawa: Statistics Canada; 2010. Available at: http://www4.hrsdc.gc.ca/.3ndic.1t.4r@-eng.jsp?iid=33 (accessed June 17, 2014).

2. Svenson JE. Patterns of use of emergency medical transport: a population based study. Am 7 Emerg Med 2000;18(2): $130-4$.

3. Lowthian JA, Jolley DJ, Curtis AJ, et al. The challenges of population ageing: accelerating demand for emergency ambulances services by older patients, 1995-2015. Med $\mathcal{7}$ Aust 2011;194(11):574-8.

4. Shah MN, Bazarian JJ, Lerner EB, et al. The epidemiology of emergency medical services use by older adults: an analysis of the National Hospital Ambulatory Medical Care Survey. Acad Emerg Med 2007;14(5):441-7.

5. Wofford JL, Schwartz E, Byrum JE. The role of emergency services in health care for the elderly: a review. 7 Emerg Med 1993;11(3):317-26.

6. Goldstein J, Jensen JL, Carter AJ, et al. Epidemiology of prehospital emergency responses for older adults in a provincial emergency medical services system. CFEM 2013;15(Suppl 1):S72.

7. Hastings NS, Purser JL, Johnson KS, et al. Frailty predicts some but not all adverse outcomes in older adults discharged from the emergency department. 7 Am Geriatr Soc 2008; 56(9):1651-7.

8. Stiffler KA, Finley A, Midha S, et al. Frailty assessment in the emergency department. $\mathcal{F}$ Emerg Med 2013;45(2):291-8.

9. Goldstein J, Hubbard RE, Moorhouse P, et al. The validation of a care partner-derived frailty index based upon comprehensive geriatric assessment (CP-FI-CGA) in emergency medical services and geriatric ambulatory care. Age Ageing 2015;44(2):327-30. 
10. Fried LP, Tangen CM, Walston J, et al. Frailty in older adults: evidence for a phenotype. $\mathcal{f}$ Gerontol A Biol Sci Med Sci 2001;56(3):M146-56.

11. Mitnitski AB, Mogilner AJ, Rockwood K. Accumulation of deficits as a proxy measure of aging. ScientificWorldfournal 2001;1:323-36.

12. Joseph B, Pandit V, Rhee P, et al. Predicting hospital discharge disposition in geriatric trauma patients: Is frailty the answer? 7 Trauma Acute Care Surg 2014;76(1):196-200.

13. Bagshaw SM, Stelfox HT, McDermid RC, et al. Association between frailty and short- and long-term outcomes among critically ill patients: a multicentre prospective cohort study. CMA7 2014;186(2):E95-102.

14. Cooney DR, Millin MG, Carter A, et al. Ambulance diversion and emergency department offload delay: resource document for the National Association of EMS Physicians position statement. Prehosp Emerg Care 2011;15(4):555-61.

15. Martinez R, Carr B. Creating integrated networks of emergency care: from vision to value. Health Aff (Millwood) 2013;32(12):2082-90.

16. Jensen JL, Travers AH, Bardua DJ, et al. Transport outcomes and dispatch determinants in paramedic long-term care program: a pilot study. CFEM 2013;15(4):206-13.

17. Mason S, Knowles E, Freeman J, et al. Safety of paramedics with extended skills. Acad Emerg Med 2008;15(7):607-12.

18. Vetter NJ. Effects of an aging population on service use. Rev Clin Geront 2006;15(1):55-62.

19. Gruneir A, Silver MJ, Rochon PA. Emergency department use by older adults: a literature review on trends, appropriateness, and consequences of unmet health care needs. Med Care Res Rev 2011;68(2):131-55.

20. Fried TR, Tinetti ME, Iannone L, et al. Health outcome prioritization as a tool for decision making among older persons with multiple chronic conditions. Arch Intern Med 2011;171(20):1854-6.

21. Rockwood K, Mitnitski A. Frailty, fitness, and the mathematics of deficit accumulation. Rev Clin Gerotol 2007;17(1):1-12.

22. Lacas A, Rockwood K. Frailty in primary care: a review of its conceptualization and implications for practice. BMC Med 2012;10:4.

23. Rockwood K, Song X, MacKnight C, et al. A global clinical measure of fitness and frailty in elderly people. CMAJ 2005;173(5):489-95.

24. Rockwood K, Mitnitski A. Frailty defined by deficit accumulation and geriatric medicine defined by frailty. Clin Geriat Med 2011;27(1):17-26.

25. Goldstein J, Travers A, Hubbard R, et al. Assessment of older adults by emergency medical services: methodology and feasibility of a care partner Comprehensive Geriatric Assessment (CP-CGA). CFEM 2014;16(5):370-7.

26. Clarfield AM, Bergman H, Kane R. Fragementation of care for frail older people-an international problem. Experience from three countries: Israel, Canada, and the United States. 7 Am Geriatr Soc 2001;49(12):1714-21.

27. Turner G, Clegg A. Best practice guidelines for the management of frailty: a British Geriatrics Society, Age UK and Royal College of General Practitioners report. Age Ageing 2014;43(6):744-7.
28. Fit for Frailty-consensus best practice guidance for the care of older people living in community and outpatient settingsa report from the British Geriatrics Society 2014. Available at: http://www.bgs.org.uk/campaigns/fff/fff_full.pdf (accessed on May 8, 2014).

29. Goldstein J, Rockwood K. Frailty in older pre-hospital patients: properties of a Clincal Frailty Scale [Abstract]. Prehosp Emerg Care 2012;16(1):164.

30. Shah MN, Lerner EB, Chiumento S, et al. An evaluation of paramedic's ability to screen older adults during emergency responses. Prehosp Emerg Care 2004;8(3):298-303.

31. Williams JG, Bachman MW, Jones AW, et al. Retrospective validation of a protocol to limit unnecessary transport of assisted-living residents who fall. Prehosp Emerg Care 2015;19(1):68-78.

32. Kue R, Ramstrom E, Weisberg S, et al. Evaluation of an emergency medical services-based social services referral program. Prehosp Emerg Care 2009;13(3):273-9.

33. Goldstein JP, Andrew MK, Travers A. Frailty in older adults using pre-hospital care and the emergency department: a narrative review. Can Geriatr 7 2012;15(1):16-22.

34. McCusker J, Bellavance F, Cardin S, et al. Detection of older people at increased risk of adverse health outcomes after an emergency visit: the ISAR screening tool. $7 \mathrm{Am}$ Geriatr Soc 1999;47(10):1229-37.

35. Meldon SW, Mion LC, Palmer RM, et al. A brief riskstratification tool to predict repeat emergency department visits and hospitalizations in older patients discharged from the emergency department. Acad Emerg Med 2003; 10(3):224-32

36. Lee J, Verbeek R, Morrison L, et al. Paramedics assessing elders at risk for independence loss (PERIL): feasibility and inter-rater reliability of risk factors for adverse outcomes [abstract]. Acad Emerg Med 2007;14(5):S19.

37. Lee JS, Verbeek RP, Kiss A, et al. Paramedics assessing elders at risk of independence loss (PERIL): nontransportation rates of older clients in 3 EMS systems. C7EM 2009;11(3):263.

38. McCusker J, Verdon J, Tousignant P, et al. Rapid emergency department intervention for older people reduces risk of functional decline: results of a multicenter randomized trial. 7 Am Geriatr Soc 2001;49(10):1272-81.

39. Carpenter CR, Shah MN, Hustey FM, et al. High yield research opportunities in geriatric emergency medicine: prehospital care, delirium, adverse drug events, and falls. 7 Gerontol A Biol Sci Med Sci 2011;66(7):775-83.

40. Mason S, Knowles E, Colwell B, et al. Effectiveness of paramedic practitioners in attending 999 calls from elderly people in the community: cluster randomised controlled trial. BM7 2007;335(7626):919.

41. Bigham BL, Kennedy SM, Drennan I, et al. Expanding paramedic scope of practice in the community: a systematic review of the literature. Prehosp Emerg Care 2013;17(3):361-72.

42. Brown LH, Hubble MW, Cone DC, et al. Paramedic determiniations of medical necessity: a meta-analysis. Prehosp Emerg Care 2009;13(4):516-27.

43. County of Renfrew Paramedic Service. Aging at Home. Community Paramedic; 2011. Available at: http://www. communityparamedic.ca/pages/home/aging-at-home.php (accessed January 13, 2015). 
44. Ruest M, Stitchman A, Day C. Evaluating the impact on 911 calls by an in-home programme with a multidisciplinary team. Int Paramedic Prac 2012;1(4):125-32.

45. Toronto Emergency Medical Services. Community Paramedicine. Available at: http://www.torontoems.ca/main-site/service/community-paramedicine.html (accessed January 13, 2015).

46. Drennan IR, Dainty KN, Hoogeveen P, et al. Expanding Paramedicine in the Community (EPIC): study protocol for a randomized controlled trial. Trials 2014;15:473.

47. Newton M, Tunn E, Moses I, et al. Clinical navigation for beginners: the clinical utility and safety of the Paramedic Pathfinder. Emerg Med 7 2014;31(e1):e29-34.

48. Munjal K, Carr B. Realigning reimbursement policy and financial incentives to support patient-centered out-ofhospital care. FAMA 2013;309(7):667-8.
49. Kovner CT, Mezey M, Harrington C. Who cares for older adults? Workforce implications of an aging society. Health Aff (Millwood) 2002;21(5):78-89.

50. Shah MN, Rajasekaran K, Sheahan WD, et al. The impact of the geriatrics education for emergency medical services training program in a rural community. $7 \mathrm{Am}$ Geriatr Soc 2008;56(6):1134-9.

51. Shah MN, Swanson PA, Nobay F, et al. A novel internet-based geriatric education program for emergency medical service providers. 7 Am Geriatr Soc 2012;60(9): 1749-54.

52. Carpenter CR, Platts-Mills T. Evolving prehospital, emergency department, and "inpatient" management models for geriatric emergencies. Clin Geriatr Med 2013; 29(1):31-47. 